\title{
CULTURA: COMUNICAÇÃO, ARTE, ORALIDADE NA PRÉ-HISTÓRIA DO BRASIL
}

Maria Dulce Gaspar*

GASPAR, M.D. Cultura: comunicação, arte, oralidade na pré-história do Brasil. Rev. doMuseu de Arqueologia e Etnologia, São Paulo, 14: 153-168, 2004.

RESUMO: Esse artigo tem como objetivo apresentar reflexões sobre artefatos dos caçadores-coletores, sambaquieiros e Tupinambá que se destacam aos nossos olhos devido ao forte apelo estético. São pinturas rupestres, esculturas em pedra e vasos de cerâmica que, através do sistema de comunicação impresso na cultura material, perenizaram temas estruturais dessas diferentes sociedades.

\section{UNITERMOS: Pintura rupestre-Zoólitos - Cerâmica Tupinambá.}

\section{Introdução}

Diferentes grupos ocuparam o que é hoje o território brasileiro até a invasão européia. Portugueses, espanhóis, franceses e holandeses, em pleno mercantilismo, chegaram no que se convencionou chamar de Novo Mundo trazendo muitas novidades. Trouxeram caravelas, armas de fogo, doenças e o hábito de escrever um sofisticado sistema de comunicação inexistente no continente americano. Os nativos valiam-se da tradição oral e perenizavam suas idéias em artefatos impregnados de simbolismo. Esse artigo versa sobre estas outras formas de comunicação.

Inicio apresentando uma síntese sobre a evolução da oralidade e logo após apresento um breve resumo da colonização do território que corresponde ao Brasil, no período anterior à chegada dos europeus. Segue reflexão sobre cultura material e comunicação e, dessa forma, apresento os termos indicados no título - oralidade

(*) Museu Nacional da Universidade Federal do Rio de Janeiro -UFRJ mgaspar@alternex.com.br cultura, comunicação e pré-história do Brasil. Em decorrência da diversidade de registros arqueológicos que caracteriza o Brasil pré-colonial, deter-meei na análise de três estudos de caso: as pinturas e gravuras feitas pelos caçadores, as esculturas dos sambaquieiros e as cerâmicas dos Tupi. ${ }^{1}$

\section{Oralidade}

Bruna Franchetto e Yone Leite, ao analisarem diferentes mitos sobre a origem dos ancestrais, ressaltam que é impossível se imaginar um ser superior ou um herói civilizador que não seja dotado da mais importante faculdade do homem: a linguagem. Ressaltam, ainda, que esta faculdade não se limita à nomeação de coisas e ao enfileirar linear aleatório de palavras. Exige mecanismos bem mais complexos de associação entre coisas e palavras, a correlação entre palavra e sentença, a

(1) Muitas das minhas reflexões aqui apresentadas integram os meus livros Sambaqui: arqueologia do litoral brasileiro e $A$ arte rupestre no Brasil, ambos publicados pela Jorge Zahar Editora. 
GASPAR, M.D. Cultura: comunicação, arte, oralidade na pré-história do Brasil. Rev. do Museu de Arqueologia e Etnologia, São Paulo, 14: 153-168, 2004.

formação de frases, os mecanismos que permitem o encaixe de sentenças umas dentro de outras. Mais adiante destacam que as estruturas produzidas pela linguagem humana são infinitas, porque cada frase é uma nova criação, ou seja, nunca se diz a mesma coisa do mesmo modo (Franchetto e Leite 2004: 10-11, 43) (grifo meu).

Continuando com as autoras, elas demonstram que a questão da origem da linguagem ou, em outros termos, da evolução do comportamento comunicativo humano está relacionada à própria evolução humana. Relembram que todos nós temos um ancestral comum que viveu entre 100 e $60 \mathrm{mil}$ anos atrás na África e destacam que a verdadeira transição para a humanidade moderna teria ocorrido na passagem do Paleolítico médio ao Paleolítico recente, ou seja, em torno de 50 mil anos atrás. Neste período, ocorreram mudanças surpreendentes na fabricação de utensílios que são marcadas pela criatividade individual (Franchetto e Leite 2004: 30)

Há 40 mil anos, as inúmeras invenções humanas atestam o momento em que a evolução cultural substituiu a biológica no que se refere a seu valor adaptativo. É o período que Walter Neves e André Prous (2000: 32-33) denominam de "a explosão criativa", quando ocorrem as manifestações artísticas, uso de diferentes tipos de matériasprimas (ossos, chifres e dentes), confecção de roupas e tecidos, refinamento da industria lítica, ritualização dos sepultamentos com grande quantidade de oferendas mortuárias, aumentos dos grupos nucleares que se articulam em comunidades maiores. Segundo os autores, é a criatividade o marco do Paleolítico Superior. O homem anatomicamente moderno, munido, nesse período, "de uma criatividade ilimitada, de capacidade de comunicação simbólica e de grande plasticidade comportamental" expandiu-se e dominou rapidamente o planeta (Neves e Prous 2000: 32-33).

Segundo Franchetto e Leite (2004: 30) "é difícil imaginar uma transformação tão rápida e profunda sem considerar o papel crucial de uma linguagem já com todos os elementos das línguas modernas. Em outras palavras, data-se dessa época a existência de uma primeira língua".

Independente da data inaugural de colonização das Américas, como diz Tânia Andrade Lima (no prelo), este continente foi a derradeira grande massa de terra a ser ocupada pela espécie humana em um movimento que representa a última etapa da longa e bem sucedida história da migração e dispersão do gênero Homo pelo planeta Terra. Os grupos que colonizaram o que é hoje o território brasileiro já apresentavam o que Neves e Prous (2000: 33) denominam de "comportamento moderno" cuja característica principal é a criatividade Os primeiros caçadores que aqui chegaram contavam com capacidade de comunicação simbólica e este recurso foi um fator importante na conquista de novas terras.

Apesar do investimento dos lingüistas em estudar línguas antigas pouco se sabe sobre o falar dos primeiros caçadores (que aqui chegaram por volta de 12.500 anos), dos sambaquieiros (que já estavam na costa brasileira há mais de 7 mil anos).

No momento da Ciência Nacional, artefatos produzidos pelos caçadores e sambaquieiros, que se preservaram da destruição causada pelo transcorrer do tempo, são o melhor caminho para caracterizá-los e entender os seus sistemas de comunicação. Situação bem distinta ocorre com os Tupi cujos falantes estão entre nós.

\section{Ocupação do Brasil antes da invasão européia}

O que é atualmente o território brasileiro está repleto de testemunhos arqueológicos que guardam importantes evidências da história da colonização humana em nosso continente. São os vestígios dos caçadores que iniciaram a ocupação da América do Sul, os monumentais sambaquis do litoral, as inúmeras aldeias de grupos ceramistas dispersas por todo o país, sítios arqueológicos que contêm informações sobre o passado do que é hoje o território brasileiro e a diversidade cultural que foi, passo a passo, aqui se instalando.

O modelo clássico que pretende dar conta do processo de colonização das Américas postula que os primeiros grupos alcançaram o continente americano atravessando o estreito de Bering, aproveitando a "ponte" formada entre a Sibéria e o Alasca por volta de 18 e 13 mil anos atrás, em decorrência de mudanças climáticas que resultaram no recuo da linha da costa e, por conseguinte, na exposição de amplas planícies litorâneas. Os primeiros caçadores teriam seguido a migração dos grandes animais (bisonte, cavalo, mamute, caribu) através desse caminho, denominado Beríngia. Ao chegar à Grande Planície no centro da América do Norte, a ação humana e um acentuado crescimento 
demográfico teriam levado à extinção dos grandes animais. Para sobreviver, teriam migrado cada vez mais para o sul, acabando por atingir a Terra do Fogo.

Supunha-se, também, que os primeiros grupos que chegaram à América do Sul compartilhariam certas semelhanças com os primeiros colonizadores da América do Norte. Esperava-se encontrar no que é hoje o território brasileiro indícios característicos dos caçadores especializados em animais de grande porte, como o mamute e o bisonte.

Levando em conta que não há indícios seguros de que os homens tenham primeiro chegado à América do Sul para depois ocupar a do Norte, supunha-se que eles teriam colonizado o nosso continente por volta de 10 mil anos atrás. Caçadores teriam cruzado o istmo do Panamá e seguido pela Colômbia até atingir a extremidade sul das Américas. Segundo essa hipótese, o continente teria sido povoado em apenas 500 anos, numa espécie de corrida migratória. Os resultados das pesquisas realizadas no sítio Monte Verde, no sul do Chile, trouxeram nova luz a este debate. Thomas Dillehay (1997) obteve datações de 12.800 anos AP, comprovando com isso uma ocupação no final do Pleistoceno distinta da empreendida na América do Norte. Pesquisas que estão sendo realizadas em sítios antigos no Brasil indicam, ainda, que o estilo de vida era bastante diferente dos caçadores de animais que ocuparam as planícies da América do Norte.

Os estudos de Renato Kpnis (1998) informam que, diferente do que havia sido proposto, os primeiros ocupantes do Brasil Central eram principalmente coletores e que a sua indústria lítica caracterizava-se pela presença de raspadores utilizados no trabalho da madeira e de algumas poucas pontas de projétil. Os restos botânicos indicam a exploração de coquinhos, guariroba, licuri, chichá (amendoim-de-bugre), pequi, jatobá e outros frutos do cerrado. A caça tinha como presa animais de pequeno e médio porte (roedores, tatus, primatas, preguiças, lebres, antas), répteis, aves e peixes. Animais maiores, tais como veado, porcodo-mato, anta são raros nos momentos iniciais, sendo mais recorrentes no final. Para o autor, não há nenhuma evidência clara de caça à megafauna e, como bem demonstra, trata-se de um modo de vida bem diferente daqueles dos caçadores de grandes animais que ocuparam a América do Norte. Estes grupos aprenderam a explorar a grande diversidade de recursos disponíveis nos novos ambientes tropicais.

Os estudos de sítios dos primeiros colonizadores e uma série de datações antigas que tinham sido obtidas em diferentes estados do país -

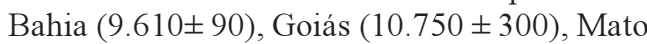
Grosso (10.405 \pm 100$)$, Mato Grosso do Sul $(10.340 \pm 110)$, Minas Gerais (12.330 \pm 230$)-$ confirmam a existência de grupos humanos em época recuada. Alguns pesquisadores acham que a ocupação do Brasil é ainda mais antiga e certamente novas escavações vão liberar informações que podem ser surpreendentes. Pois, se de fato as primeiras populações que ocuparam as Américas, atravessando o estreito de Bering, cruzaram a América do Norte e a Central para só depois chegar à do Sul, e se Monte Verde, no extremo sul do continente americano, foi ocupado por volta de 12.500 anos AP, é possível que sejam encontrados testemunhos mais antigos no território brasileiro. Fabio Parenti (1996) obteve uma série da datas bem recuadas para sítios no Parque Nacional da Serra da Capivara, e tem discutido o tema com pertinência, mas sem total aceitação pela comunidade de arqueólogos. $\mathrm{O}$ sítio Boqueirão da Pedra Furada apresenta datas que se aproximam de 50 mil anos. Niéde Guidon (2004:138), apoiada em novos resultados de pesquisa, considera que a ocupação da região remonta a 100 mil anos antes do presente.

Como sugere Paulo De Blasis (2001), apesar da escassez e fragilidade das evidências existentes, um crescente número de pesquisadores começa a aceitar a idéia de que o homem teria penetrado na América em datas mais recuadas, aproveitando diferentes momentos da formação da passagem pelo estreito de Bering, criando condições para que diferentes levas de grupos humanos migrassem para o continente americano.

É natural que o debate ocorra e seja acalorado, pois a arqueologia é uma Ciência Social que se constrói acumulando conhecimento produzido pela comunidade de arqueólogos e, como os demais campos de saber, é integrada por estudiosos que abraçam hipóteses distintas. Como toda ciência, cabe aos pesquisadores que inovam o ônus da prova.

Acumula-se, no Brasil e na América do Sul, uma série de informações sobre sítios antigos; agora, saber exatamente quando este processo começou e demonstrar toda a sua complexidade 
vai exigir dos cientistas muito mais pesquisa. Neste momento, é importante saber que as informações disponíveis asseguram que a partir de 12.000 AP o território brasileiro já estava ocupado e que há indícios de que muito cedo os caçadores decoraram as paredes rochosas com grafismos. Mais ainda, que este hábito perdurou até o período de contato com os europeus. Como os caçadores que ocuparam outros continentes já decoravam paredões há muito tempo, é bem provável que os primeiros ocupantes das Américas tenham trazido em sua bagagem cultural o hábito de decorar as paredes de pedra. Parece correto apoiar esta hipótese já que na Europa, na gruta Chauvet, na Ardèche, França, os registros gráficos se situam entre 32.000 e 31.000 anos (Pessis 2003:53), na Austrália, as primeiras manifestações estão datadas de 40 mil anos (Bahn, 1998).

A elaboração de objetos com esmerado apelo estético está presente muito cedo no processo de colonização do Brasil sendo um hábito difundido entre pescadores-coletores. Os construtores de sambaqui que ocuparam a região Sul e Sudeste elaboraram belíssimas esculturas em pedra e osso que representam figuras humanas, animais aquáticos, aves, espécie de rodas denteadas ou engrenagens.

Em decorrência da grande diversidade de testemunhos arqueológicos focarei apenas três tipos de manifestações dos grupos que ocuparam o Brasil. Centrarei essa análise nos caçadores que realizaram as pinturas rupestres, especialmente as que integram o conjunto denominado de tradição nordeste; nos sambaquieiros que elaboraram esculturas de pedra e osso e nos Tupi, especialmente os Tupinambá, que fabricaram cerâmicas multicoloridas.

Já adiantei algumas informações sobre o modo de vida dos primeiros caçadores que chegaram ao território brasileiro e agora passo a enfocar os que ocuparam a região Nordeste, incluindo aí o norte do estado de Minas Gerais, onde ocorrem pinturas e gravuras que representam homens, emas, cervídeos e que se caracterizam pela presença de figuras humanas formando cenas de caça, dança, guerra, sexo e rituais. Há nesses grafismos uma profusão de informações sobre a rotina dos artistas e de seu grupo. Eles carregam bastões, cestas, usam propulsores e inúmeros outros objetos (Fig. 1).

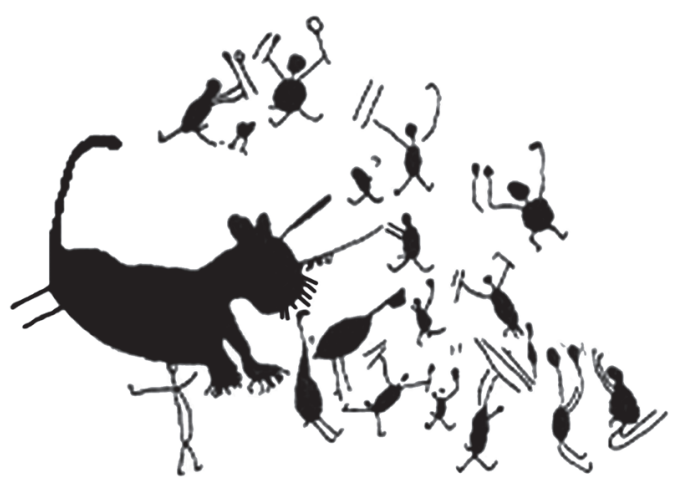

Fig. 1 - São Raimundo Nonato, PI. Martin 1999: 273.

Segundo Anne-Marie Pessis (2003 : 47), os autores das pinturas de São Raimundo Nonato, Piauí, viviam fora dos abrigos. Habitavam aldeias, geralmente situadas sobre terrenos planos, no alto da chapada, perto de fontes d'água. Além dos grafísmos, os demais vestígios são pouco abundantes e restringem-se à industria lítica. Nas aldeias não existe estratigrafia, o material arqueológico encontrase na superfície, pois não há deposição de sedimento para recobrir os testemunhos arqueológicos.

As reflexões sobre as esculturas apóiam-se na análise detalhada feita por Castro Faria $(1952,1959)$ e André Prous (1977), sendo a reconstituição do modo de vida dos sambaquieros nos estudos realizados nos sambaquis do sul de Santa Catarina (Gaspar et al 1999, Fish et al 2000, Gaspar 2000, Klokler 2001). Os pescadores-coletores ocuparam parte significativa da costa brasileira, mas tratarei aqui apenas dos testemunhos compreendidos entre o vale do rio Ribeira, São Paulo e o litoral de Torres, Rio Grande do Sul, faixa litorânea onde ocorrem sambaquis dos quais foram recuperadas as esculturas.

Em decorrência da variação do nível do mar que arrasou os registros mais antigos dos pescadores-coletores, não se sabe ao certo quando eles chegaram até a costa do Brasil. Há datações isoladas de 9 mil e 10 mil anos que precisam ser confirmadas, mas é certo que por volta de 7 mil anos o litoral começava a ser intensamente ocupado.

A principal atividade de subsistência dos sambaquieiros era a pesca, complementada pela coleta de vegetais e moluscos. O cuidado com os mortos era um aspecto da vida social que tinha especial importância para eles. Corpos de 
homens, mulheres e crianças eram preparados, muito provavelmente descarnados embora os ligamentos fossem mantidos, parecem ter sido acomodados em um fardo e sepultados em locais especialmente construídos para recebê-los. Atualmente, estes locais caracterizam-se pela concentração de carapaças de moluscos e ossos de peixe, são restos faunísticos que resultaram dos alimentos oferecidos aos mortos e consumidos junto a eles. Acompanhava o morto abundante quantidade de comida - peixes de grande porte, mamíferos,...- e periodicamente o grupo de afinidade retornava ao cemitério e realizava festins cujos restos eram depositados sobre a área funerária formando enormes montes que ultrapassam $1 \mathrm{~m}$ de altura.

A análise zooarqueológica indica dois tipos de peixes capturados e cujos restos estão presentes no sambaqui: 1 os que acompanhavam os mortos - aqui considerados como oferenda mortuária, 2 os que integram o festim fúnebre cerimônia em que o grupo se reunia para reverenciar os seus mortos e com eles comungar. A oferenda mortuária é basicamente composta de peixes de grande porte e de alguns mamíferos, já o festim fúnebre é integrado por peixes de pequeno porte e moluscos. São alimentos distintos e obtidos através de procedimentos específicos (Klokler 2001)

Completava a cerimônia fúnebre o fogo ritual. Logo acima do corpo era acesa uma fogueira que cobria a cova. Há indícios de que o fogo ardia durante um longo período e ao finalizar a fogueira, as cinzas eram logo cobertas com moluscos. $\mathrm{O}$ fogo, também, estava presente no festim fúnebre e as linhas de fogueira que cobrem toda a área funerária indicam a periodicidade das cerimônias. A repetição do programa funerário, ao longo de centenas de anos, resultou no incremento do sambaqui que, em alguns casos, chegou a atingir mais de 25m de altura (Fish e colaboradores 2000; Klokler 2001).

As esculturas recuperadas em contexto arqueológico, também, integravam o ritual funerário e reforçam a idéia de que o culto aos antepassados era aspecto importante na vida social dos sambaquieiros. Guilherme Tiburtius elaborou um dos únicos registros de esculturas durante uma escavação, o croqui mostra claramente como as várias esculturas integravam a parafernália ritual (Gaspar 2000:19) (Fig. 2).

Já os Tupi eram agricultores e ceramistas sendo a base de sua subsistência a mandioca. As línguas do tronco Tupi descendem de uma língua ancestral falada há cerca de 5.000 mil anos na região Amazônica. Em decorrência de mudanças econômicas e sociais que ocorreram nos modos de vidas dos grupos que habitavam a Amazônia por volta de 2.000 anos atrás, se deu a sua expansão territorial para o sul e sudeste do Brasil. As vias de expansão e os territórios ocupados são facilmente

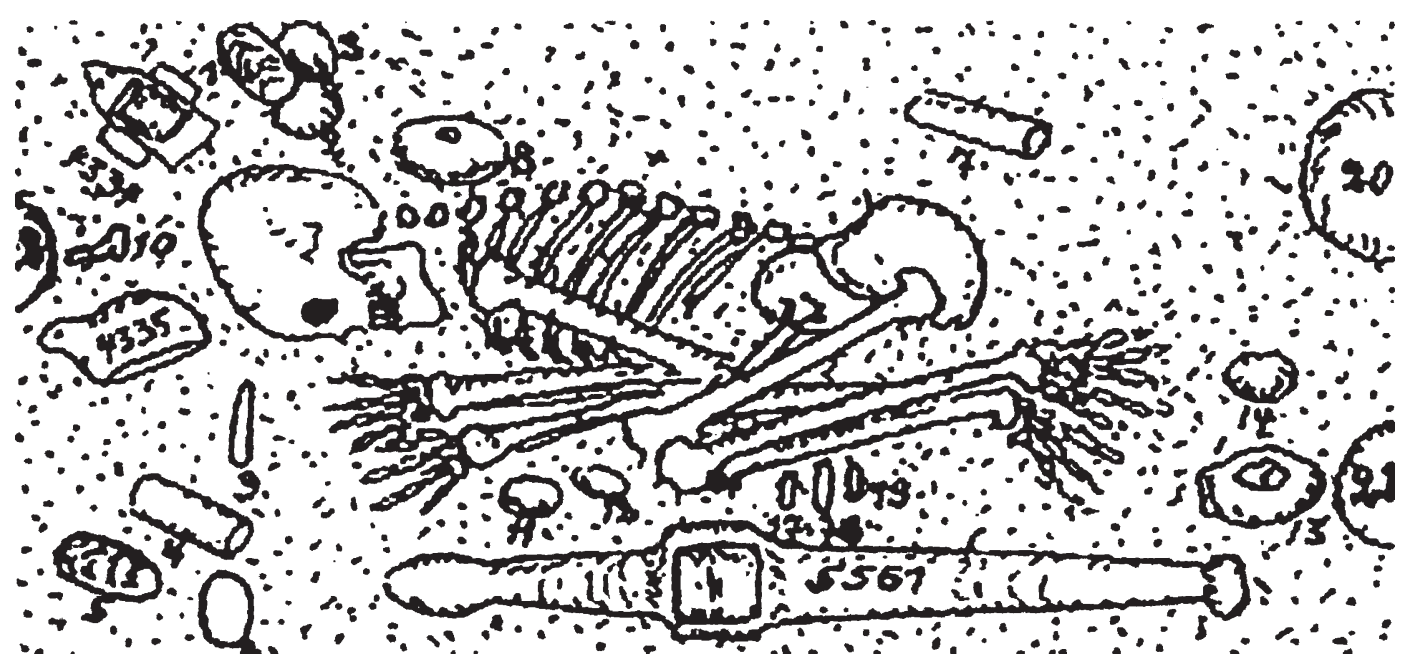

Fig. 2 - Croqui de sepultamento. Gaspar 2000: 19. 
GASPAR, M.D. Cultura: comunicação, arte, oralidade na pré-história do Brasil. Rev. do Museu de Arqueologia e Etnologia, São Paulo, 14: 153-168, 2004.

identificados em decorrência de sua indústria cerâmica que guarda traços diagnósticos.

Os vasilhames são bem característicos com uma pintura policrômica em vermelho e/ou preto sobre base branca. Finos desenhos geométricos, em cor preta, apontam para o esmero estético com que os vasilhames eram decorados. Há também decorações plásticas que foram feitas antes que a argila secasse, ocorrem impressões de dedos, de unha, de espigas ou de estiletes (Buarque, no prelo) (Fig. 3).

Segundo Silva, Neves e De Blasis (2004:11), o modo de ser Tupi baseia-se numa "organização social flexível, um poder político baseado no prestígio e na importância religiosa do indivíduo, e que compartilham um mundo espiritual e ritual onde xamanismo, a guerra e o canibalismo são noções extremamente importantes para a construção de sua identidade".

Todos esses artefatos aqui mencionados são impregnados de simbolismo e é preciso destacar que os ocupantes do Brasil antes da invasão européia já contavam com inúmeros objetos representativos (pinturas, gravuras, esculturas e cerâmicas). Isso indica que em nenhum momento da colonização do Brasil, escolhas e decisões foram feitas levando em conta apenas necessidades práticas tais como correr atrás da grande caça para não morrer de fome ou migrar em busca de novos bancos de moluscos. Ao contrário, houve significativo investimento na produção de objetos que integravam os sistemas de comunicações específicos a cada grupo, sistema que era composto principalmente pela linguagem articulada.

Caçadores e pescadores-coletores tinham territórios bem distintos, os primeiros espalharamse pelo interior do Brasil e os segundos exploraram intensivamente a faixa litorânea. Por volta de 2.000 anos atrás uma ebulição cultural ocorreu na Amazônia envolvendo crescimento demográfico, mudanças profundas na economia e na organização social das populações que habitavam a região. Dentre esses eventos há o surgimento de grandes aldeias na Amazônia, Brasil Central e Pantanal que indica crescimento populacional e adoção de um estilo de vida mais sedentário e mais dependente da agricultura do milho e mandioca. Inaugura-se, assim, uma nova maneira de manejar o ambiente e transformar a paisagem.

São manifestações dessa efervescência cultural que passo a passo foi se instalando na Amazônia e repercutiu em toda a América do Sul, os grandes aterros e as cerâmicas pintadas e modeladas que representam homens e animais da ilha de Marajó (há 1.600 anos atrás), os enormes sítios existentes no médio Amazonas onde são encontradas urnas

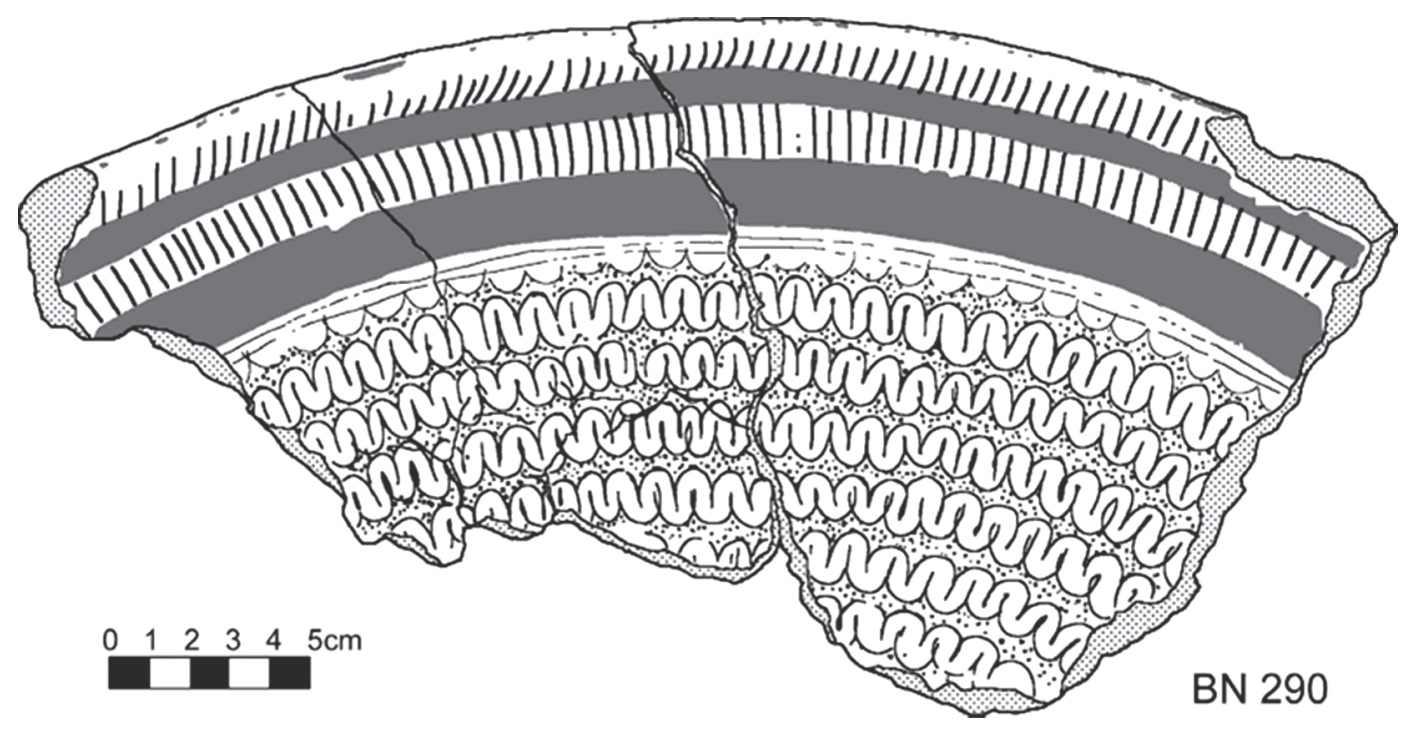

Fig. 3 -Cerâmica Tupi. A. Buarque, As estruturas funerárias dos sítios arqueológicos de Araruama, RJ. (no prelo). 
GASPAR, M.D. Cultura: comunicação, arte, oralidade na pré-história do Brasil. Rev. do Museu de Arqueologia e Etnologia, São Paulo, 14: 153-168, 2004.

funerárias Guarita com formas humanas (datadas de cerca de 1.200 e 500 anos atrás) e a sociedade que se desenvolveu na região do baixo Tapajós e que produziu elaborados vasos, denominados de cariátides além de estatuetas antropomorfas (Silva, Neves e De Blasis 2004). Estas mudanças sociais inauguraram e difundiram o hábito de decorar vasilhames cerâmicos com pintura policrômica com amplo uso das cores vermelha, preta e branca.

Assim, com os deslocamentos populacionais que ocorreram na Amazônia e no Brasil Central se dá todo um rearranjo dos grupos sociais que aqui habitavam. ${ }^{2}$ Houve deslocamentos de populações e contatos interétnicos ocorrendo significativa interação social, interação que alimenta a esperança de que elementos do falar dos caçadores e pescadores-coletores tenham sobrevivido nas línguas que compõem o ameríndio. Esta idéia não é e nem pretende ser uma hipótese de pesquisa, tem apenas a intenção de destacar que os primeiros caçadores e os pescadores-coletores já chegaram aqui com linguagem articulada e um sistema de comunicação moderno. Porém, se lingüistas pesquisam uma única língua ancestral, pode-se esperar que especialistas no assunto obtenham pistas sobre o falar destes primeiros colonizadores do território brasileiro.

\section{Cultura material e comunicação}

Franchetto e Leite (2004:40 e 30) ressaltam que o desenvolvimento da linguagem se deu quando as relações sociais entre os homens se tornaram mais complexas. Trata-se do momento em que a evolução cultural substituiu a biológica em termos de seu valor adaptativo.

Cultura, segundo proposição de Clifford Geertz, é um conjunto de mecanismos de controle - planos, receitas, regras, instruções - que governa o comportamento. Dessa forma, a cultura é um contexto e é através do fluxo do comportamento - da ação social - que as formas culturais encontram articulação. Esta articulação se dá, também, através de várias espécies de artefatos (Geertz 1978: 56, 24, 27).

Dois dos estudos de caso aqui considerados caçadores e sambaquieiros - referem-se a contex-

(2) Um panorama dos deslocamentos populacionais é fornecido por Noelli (2000). tos culturais em que não é possível analisar o comportamento ou o discurso tendo como o único testemunho de sua presença o registro arqueológico. Portanto, cabe esclarecer as especificidades da cultura material para que se possa pensar o sistema de comunicação destes dois grupos sociais.

A arqueologia é a ciência que estuda as culturas a partir do seu aspecto material, construindo suas interpretações através da análise dos artefatos, seus arranjos espaciais e sua implantação na paisagem. Cultura material aqui entendida da maneira proposta por Ulpiano Bezerra de Meneses (1983:112) como o segmento do meio físico que é socialmente apropriado. Apropriação esta que não é aleatória, casual ou individual, mas que segue padrões sociais. Assim, o conceito pode abranger artefatos, modificações da paisagem e o próprio corpo, na medida em que ele é passível de manipulação.

A cultura material é o suporte material, físico, concreto da produção e reprodução da vida social. Nesse sentido, os artefatos são considerados sob duplo aspecto: como produtos e como vetores das relações sociais. De um lado, eles são o resultado de certas formas específicas e historicamente determináveis de organização dos homens em sociedade. De outro lado, eles canalizam e dão condições a que se produzam e efetivem, em certas direções, as relações sociais (Bezerra de Meneses 1983: 113).

Ian Hooder, (1982) em trabalho seminal para a arqueologia moderna, propõe a concepção de cultura material como um sistema de representação. Assim, pode-se considerar que a arqueologia é o estudo da cultura material como manifestação de práticas simbólicas significativas, constituídas e situadas em relação ao social. Ainda segundo Hodder (1999), a cultura material é uma construção e um meio de comunicação envolvida em prática social. Pode ser utilizada para transformar, estocar ou preservar informação social. Também é meio simbólico da prática social, atuando dialeticamente em relação à prática. Ela pode ser considerada como um tipo de texto, uma forma silenciosa de escrita e discurso; quase literalmente, um canal de expressão reificado e objetificado.

A diversidade da vida social associada à especificidade dos objetos materiais cria potencial para transformar, através da prática, as convenções sociais. Estabelece, assim, dinâmica social com espaço tanto para a manutenção como para a transformação da cultura. 
Como o significado dos objetos se dá na relação dialética entre estrutura e prática, estes têm múltiplos significados locais. Dessa forma e retomando as idéias de Franchetto e Leite (2004), se por um lado nunca se diz a mesma coisa do mesmo modo, por outro uma mesma coisa pode ter distintos significados. A cultura material é polissêmica e leituras múltiplas convivem no mesmo espaço e tempo.

A leitura que faço dos objetos dos caçadores, sambaquieiros e Tupi só é possível a partir da perspectiva de uma sociedade que desenvolveu estudo sistemático sobre o outro e o passado. Que fez da Arqueologia uma ciência e que acumulou conhecimento que permite traçar uma confrontação de temas eleitos e de objetos elaborados em tempos e locais distintos.

\section{Arte}

Pinturas e gravuras feitas pelos nativos são expressões estéticas reconhecidas como "arte" em nossa sociedade e não é mera coincidência que este conjunto de testemunhos arqueológicos tenha sido agrupado sobre a denominação de "arte rupestre" pelos arqueólogos brasileiros. Outras manifestações com apurado esmero estético não são enquadrados na categoria ocidental de arte. Penso nas elaboradas cerâmicas da região Amazônica ou mesmo na cestaria nativa. A peneira Kayabi extremamente elaborada e de complicada execução dificilmente seria considerada arte segundo o nosso sistema de classificação que pressupõe unicidade, em muitos casos perenidade e adequação aos nossos valores estéticos. ${ }^{3}$

Como ressaltam Walter Neves e André Prous (2000: 33) falar de arte a respeito de culturas précoloniais é uma maneira ocidental e moderna de interpretar produções cujo sentido real desconhecemos. Destacam, ainda, que em várias línguas, o conceito de "arte", que designa obras criadas para o puro deleite estético, sequer existe. Trata-se de uma noção pertinente à nossa sociedade.

O domínio da arte nas sociedades nativas está particularmente integrado à rotina da comunidade, reforça tradições e está vinculado ao domínio ritual.

(3) Ver ilustração em Silva, Neves e De Blasis, 2004: 21-23.
Alguns arqueólogos chegam a sugerir que "arte" é um termo inadequado para denominar pinturas $\mathrm{e}$ gravuras. Mas arte é uma expressão já consagrada e que pode ser mantida, especialmente se tratada no sentido sugerido por André Prous (1992/93) ao enfatizar que as palavras "arte" e "artista" têm a mesma raiz latina que "artesão", sendo arte o conhecimento de regras que permitem realizar uma obra perfeitamente adequada a sua finalidade. Destaco que permeia estas regras o universo simbólico dos grupos que norteia as ações práticas necessárias para materializar o que se deseja (escolha do suporte, conjunto de técnicas, ...), seja o produto final pinturas que eternizam o ritual da árvore para os caçadores, o acasalamento dos animais para os sambaquieiros ou as vísceras dos inimigos para os Tupi.

Estes objetos, cheios de beleza para os nossos olhos, nas sociedades nativas integram sistemas de comunicações compostos por vários domínios articulados tais como fala, pintura corporal, gestos, dança que compõem, representam e reforçam a visão de mundo de cada grupo social. Anne-Marie Pessis (2003: 62), ao falar dos grafismos rupestres, propõe que as figurações, realizadas segundo convenções e códigos próprios dos diferentes grupos, teriam a função cultural de evocar acontecimentos, reais ou míticos, em torno dos quais a palavra, dita em condições rituais, completaria a mensagem, lembrada tanto em termos descritivos quanto interpretativos. Os grafismos cumpririam assim uma função social, contribuindo para registrar os conteúdos da memória grupal, sistema de comunicação social essencial à sobrevivência. Assim, só é adequado utilizar o termo arte no sentido proposto por André Prous - o conhecimento de regras que permitem realizar uma obra adequada a sua finalidade

Definidas as noções básicas sobre oralidade, cultura material, comunicação e arte, passo para os três estudos de caso elegidos.

\section{Grafismos dos caçadores}

O estudo dos grafismos está bem adiantado no Brasil e quase todo o território nacional já foi prospectado pelos cientistas, sendo que em algumas regiões, especialmente a Amazônia, os trabalhos sistemáticos só começaram nos últimos 
GASPAR, M.D. Cultura: comunicação, arte, oralidade na pré-história do Brasil. Rev. do Museu de Arqueologia e Etnologia, São Paulo, 14: 153-168, 2004.

dez anos. ${ }^{4}$ Confrontada a temática representada pelos artesãos, o estilo adotado e a implantação paisagística dos painéis foram estabelecidas oito tradições arqueológicas que são conhecidas pelas seguintes denominações: Meridional, Litorânea, Catarinense, Geométrica, Planalto, Nordeste, Agreste, São Francisco, Amazônica. ${ }^{5}$

Interessa especialmente para essa análise a tradição Nordeste que ocorre no estado do Piauí. São pinturas monocromáticas e gravuras que representam homens, animais (emas, cervídeos e pequenos quadrúpedes) e algumas figuras geométricas. Porém, o que a distingue é a abundância de antropomorfos agrupados formando cenas de caça, dança, guerra, sexo, rito, entre outras. Os humanos seguram armas (bastões, propulsores), cestas e outros objetos.

A tradição Nordeste tem a peculiaridade de ser extremamente narrativa, com a representação de diferentes aspectos da vida cotidiana do grupo que a elaborou. As pinturas indicam que caçavam com diversos instrumentos: o veado era perseguido com tacapes, a onça era atacada utilizando-se propulsores e azagaias, o tatu era caçado a mão e abatido com golpes de tacape ou pego pelo rabo. Não existe nenhuma indicação de uso de arco e flechas, no combate entre dois ou mais indivíduos, as armas utilizadas são propulsores e azagaias. Foram também representados vários ornamentos relacionados com ritos e hierarquia. São cocares e máscaras que aparecem em cenas em que as pessoas estão dançando.

As pesquisas sistemáticas desenvolvidas por Niéde Guidon, Anne-Marie Pessis e Gabriela Martin estabeleceram uma série de variações regionais decorrentes do tratamento e da dimensão das figuras, bem como das cenas representadas. Em algumas regiões é recorrente uma cena em que aparece uma grande ave dominando um conjunto de pequenas imagens, danças dirigidas por uma figura que ostenta um cocar, cenas de luta, de caça à onça, de violência e sexo, entre outras. As cenas são tão bem organizadas que provocam uma verdadeira tentação para o observador, que tem a nítida impressão de poder decodificar as mensa-

(4) Um bom exemplo de levantamentos recentes é a pesquisa de Edithe Pereira (2002).

(5) Para uma caracterização das tradições de grafismos ver Prous 1991, Martin 1996, Gaspar 2003 a. gens veiculadas pelos pintores (Martin 1996, Pessis e Guidon 2000, Pessis 2003).

Segundo Pessis e Guidon (2000), os sítios de São Raimundo Nonato possuem traços próprios que caracterizam a subtradição Várzea Grande, cujas primeiras manifestações ocorreram por volta de 12 mil anos. No seu primeiro período, são representações dinâmicas, de caráter individual, com temática lúdica, que privilegiam as figuras animais e humanas em movimento. Tecnicamente muito rebuscadas desde as primeiras manifestações, indicam que os pintores dominavam o preparo e a utilização das tintas elaboradas a partir do óxido de ferro. O apogeu dessa tradição ocorreu por volta de 10 mil anos atrás e coincide com a presença de artefatos líticos muito bem acabados. Supõe-se, ainda, que nesse período tenham ocorrido crescimento demográfico, aumento da diversidade cultural e início da dispersão do grupo pelo Nordeste.

A evolução do primeiro período é marcada pela diversidade de temas representados e pelo aumento de participantes nas cenas. Assim, como sumarizam as autoras, no primeiro momento as representações de atividades de caça comportam duas figuras, o caçador e o animal, e as representações sexuais têm dois parceiros. Já no apogeu da tradição, esses mesmos temas são representados com a participação de um maior número de pessoas. No período final, o espontaneismo inicial é substituído pela formalização gráfica, ocorrendo tanto uma geometrização notável das figuras humanas e de animais como traçados geométricos que preenchem os corpos das figuras. A temática é enriquecida com representação de ações que denotam violência: lutas, combate e execuções.

As pesquisadoras identificaram também uma evolução dos ritos, apesar de a estrutura de representação se repetir. Um dos exemplos estudados é a cena da árvore. No período inicial, há poucas pessoas participando do rito, sendo recorrentes figuras humanas isoladas mostrando uma planta na mão ou duas figuras partilhando a apresentação do vegetal. Já no período final, participa um número maior de pessoas, havendo a preocupação em indicar que todas pertencem ao sexo masculino.

Anne-Marie Pessis (2003: 103-128) ressalta que, durante os seis mil anos em que foram realizadas as pinturas da tradição Nordeste, existem temas que se repetem regularmente. São 
GASPAR, M.D. Cultura: comunicação, arte, oralidade na pré-história do Brasil. Rev. do Museu de Arqueologia e Etnologia, São Paulo, 14: 153-168, 2004.

cenas representando ritos, tanto lúdicos quanto cerimoniais, cenas de caça individual e coletiva e cenas que se referem à sexualidade. O rito está estreitamente vinculado à função de marcador de memória e para essa sociedade a caça de animais como veados, capivaras e tatus - tem notável importância no universo gráfico do grupo que decorou os paredões da Serra da Capivara. Caçador e caça são representados no ato culminante da perseguição, registrando o momento em que a caça é bem-sucedida.

Pessis (2003: 112-113) faz uma descrição acurada do sentimento que desperta ao se observar as pinturas. Segundo a autora, "A característica mais marcante do estilo Serra da Capivara é a maneira vital e dinâmica com que foram realizadas as figuras e as cenas representadas. Eclode o movimento, e a encenação transborda de alegria e ludismo. Figuras humanas e animais são mostrados em atividades lúdicas, representadas no ponto máximo de uma ação, saltando, por exemplo, com surpreendente variedade de composições e maneiras de ocupar o espaço...".

\section{Esculturas dos sambaquieiros}

Como já mencionei, o litoral do Brasil foi colonizado por um grupo denominado de sambaquieiro em decorrência do tipo de intervenção que eles fizeram na paisagem. Os sambaquis caracterizam-se basicamente por serem uma elevação de forma arredondada que chega a ter mais de $25 \mathrm{~m}$ de altura na região sul do Brasil. O registro arqueológico é constituído por conchas, ossos de peixe e de mamíferos. Contam igualmente com inúmeros artefatos de pedra e de osso, marcas de estacas e manchas de fogueira, que compõem uma intrincada estratigrafia. Os restos que mais se sobressaem na composição destes sítios são as conchas de berbigão, cujo nome científico é Anomalocardiabrasiliana (Gmelin 1971), diferentes espécies de ostras, a almejoa ou Lucina pectinata (Gmelin 1971) e os mariscos. Alguns sítios, em sua totalidade, foram espaços dedicados ao ritual funerário e lá foram sepultados homens, mulheres e crianças de diferentes idades.

O sambaqui caracteriza-se por ser um espaço diferenciado que, pelo seu volume, destaca-se na paisagem. Era o local dos mortos, um lugar particular, resultado da concentração de material orgânico. Outros materiais poderiam ter sido usados, mas a escolha recaiu sobre aqueles intrinsecamente relacionados ao domínio alimentar. O espaço em questão é um lugar bastante particular apresentando condições especiais no que se refere à textura, relevo, odores e acidez do solo.

Pesquisas arqueológicas recentes indicam que os monumentais sambaquis de Santa Catarina foram construídos por um grande número de pessoas. O sambaqui Jabuticabeira-II, um cemitério, obteve o seu volume principalmente em decorrência das atividades relacionadas com o ritual de sepultamento. ${ }^{6}$ É o resultado da repetição de cerimônias fúnebres durante mais de oitocentos anos, que envolviam a manipulação de enorme quantidade de alimentos. A repetição do ritual funerário acabou por criar um elemento obstrutivo da paisagem que, em virtude do seu tamanho e configuração, perpetua a mensagem que os seus construtores queriam transmitir. Os sucessivos eventos, diretamente relacionados com o processo de crescimento do sítio, informam para os freqüentadores da costa brasileira que aquele é o domínio dos sambaquieiros e que lá estavam os ancestrais dos pescadores-coletores. Dessa forma, o sambaqui é o resultado de um intenso trabalho social que resultou na construção de uma paisagem domesticada, marcada por referências sentimentais.

A habilidade dos sambaquieiros em elaborar artefatos ficou registrada nas esculturas de pedra e osso, objetos que impressionam pela beleza e pelo equilíbrio de formas. Já foram analisadas por Faria (1952, 1959), Gaspar (1995) e Prous (1977) fez o estudo mais detalhado. São pouco mais de 240 estatuetas, recuperadas em 40 sítios. São peças polidas que medem entre $43 \mathrm{~cm}$ e $10 \mathrm{~cm}$. A quase totalidade dos exemplares apresenta uma pequena cavidade de forma oval na parte ventral do objeto.

Prous (1977) identificou duas categorias estilísticas principais. 1-Esculturas naturalistas que representam o corpo de animais, na qual reúne peças variadas que não seguem regras estritas. 2Esculturas geométricas, em forma de cruz, de núcleo ou de triângulos, que são bastante estereotipadas. Os elementos animalísticos quando representados são mínimos e estão limitados à cabeça:

(6) Maiores informações sobre as pesquisas realizadas no sambaqui da Jabuticabeira II, Santa Catarina, podem ser obtidas em Fish e coI. 2000, Gaspar 2000 e Klokler 2001. 
GASPAR, M.D. Cultura: comunicação, arte, oralidade na pré-história do Brasil. Rev. do Museu de Arqueologia e Etnologia, São Paulo, 14: 153-168, 2004.

uma incisão para o bico, dois círculos picoteados para os olhos. Há, também, objetos que lembram engrenagens e rodas dentadas.

Alguns animais são facilmente reconhecíveis e passíveis de identificação zoológica, podendo ser estabelecida a espécie. Raia, tubarão, baleia, boto, linguado, peixe-cofre, parati, enchova, enxada, martim-pescador, pingüim, albatroz, coruja, urubu-rei, morcego, tatu, jabuti, tamanduá, cutia, tartaruga, jacaré e um felino estão entre os animais escolhidos para serem retratados em pedra e em osso.

É claro que estas esculturas são plenas de carga representativa. A simples presença da cavidade, feita para conter alguma substância, não esgota o seu significado. Como afirma Faria (1959:10), "a sua utilização, qualquer que tenha sido, estaria necessariamente ligada a atividades cerimoniais".

Para Prous (1991:223), a análise desses artefatos indicou que existe unidade ideológica na área em que ocorrem as estatuetas, evidenciada pela repetição dos temas geométricos e a obediência a regras estilísticas rígidas. O autor exemplifica sua constatação com a comparação de duas esculturas do mesmo tipo, encontradas a mais de mil quilômetros de distância e que parecem cópia uma da outra.

O conjunto de regras de fabricação das estatuetas indica que existia uma rede de comunicação na costa sul e sudeste do Brasil. O litoral cria um eixo de circulação de pessoas, nesse caso, no sentido norte-sul, um caminho natural que propicia o fluxo de comunicação em uma longa extensão. Foi a sociabilidade entre membros de comunidades distantes - o vai-evem social - que criou condições para que os sambaquieiros fossem socializados nas regras de fabrico de seus objetos.

Outros artefatos, de maneira menos evidente do que o exemplo citado por Prous, também permitem deduzir que era intenso o tráfico de informações. As técnicas empregadas na fabricação de artefatos, marcas de uso e formas recorrentes nas indústrias são indicadores dessa característica da vida social dos sambaquieiros. Indústrias líticas, ósseas, em dentes, concha e os próprios sítios são evidências de que se trata de uma cultura material produzida por grupos pertencentes a um mesmo sistema sociocultural, e que se pode inferir uma alta circulação dos seus membros, capaz de assegurar a dispersão e manutenção do acervo cultural. ${ }^{7}$

Parte significativa do conteúdo dos sambaquis está associada ao ritual funerário, as estatuetas também foram encontradas em contexto fúnebre. As esculturas que representam animais referem-se, em sua grande maioria, a seres que estão presentes no registro arqueológico na forma de restos alimentares. As exceções são alguns animais voadores (morcego, albatroz e uma ave que parece urubu-rei) e um animal que se aproxima do tamanduá. Nesse sentido, as representações parecem fazer menção ao domínio alimentar, os seres representados diferenciando-se da totalidade da dieta por serem animais que têm mobilidade. Como foi apontado por Prous, as estatuetas referem-se "a um mundo animado do qual os vegetais e os moluscos estão excluídos". São bichos que nadam, correm, voam e que podem ser surpreendidos copulando. Por compartilhar destas características é que os próprios homens também estão aí representados.

O fato de a grande maioria das esculturas apresentar a cavidade na parte ventral leva a pensar que estão referidas ao domínio da reprodução e da fertilidade. A reprodução, de maneira bem explícita, está mencionada na escultura que mostra aves copulando e a fertilidade, no objeto que apresenta um casal de peixe no momento da desova.

A categoria abundantemente representada é a dos animais marinhos. São também os que recebem tratamento mais realista, possibilitando identificar o gênero e até mesmo a espécie. Nas palavras de Castro Faria (1959), apresentam “apreciável correção anatômica". São o que o senso comum chama de "peixe". Já os animais terrestres só podem ser identificados, com total segurança, em um caso. As aves, salvo uma representação fiel de albatroz, são geralmente simples evocações.

Essa atenção dedicada aos "peixes" aponta para o ambiente a que o grupo estava mais ligado e é a chave para entender a maneira como os próprios sambaquieiros deviam se perceber. Ao invés de "coletores de moluscos", como havia sido proposto pelos pesquisadores, dada a grande

(7) Estudo detalhado sobre a similaridade da cultura material foi desenvolvido por Gaspar 2003 b para os sambaquieiros que ocuparam a Região dos Lagos, Rio de Janeiro. 
GASPAR, M.D. Cultura: comunicação, arte, oralidade na pré-história do Brasil. Rev. do Museu de Arqueologia e Etnologia, São Paulo, 14: 153-168, 2004.

quantidade de conchas no sítio arqueológico, é mais provável que eles se percebessem como pescadores, senhores do mar.

Não por coincidência, os peixes representados em esculturas são espécies que também integram a oferenda mortuária. Como já mencionei, as poucas esculturas recuperadas in situ faziam parte de uma estrutura funerária. Este arranjo espacial associa todo o investimento social em construir verdadeiros monumentos para os mortos, oferecer comida no momento do sepultamento do corpo, enterrá-los com artefatos líticos, entre eles as esculturas e o hábito de retornar inúmeras vezes para "comer" com os mortos. Todas estas evidências apontam para a importância crucial do culto aos antepassados na sociedade sambaquieira. Os mortos marcam a paisagem, sendo ponto de referência, os sambaquis guardam relíquias e alimentos abundantes assegurando o funcionamento da sociedade sambaquieira.

\section{Cerâmicas Tupi}

Segundo André Prous (1992) são encontrados sítios arqueológicos relacionados com os Tupi a curta distância dos rios navegáveis, em zonas de mata. Sendo que a ocupação corresponde à rede hidrográfica principal, como se fosse uma teia de aranha entre os fios da qual persistiram os tradicionais habitantes da região que permaneceram nos relevos mais elevados, que esse grupo canoeiro não cobiçava e onde evitava aventurar-se. Exploravam a floresta de galeria tropical ou sub-tropical e praticavam uma horticultura baseada no cultivo da mandioca, complementando a alimentação com outros cultivos, além da pesca e, em menor escala, da caça e da coleta de moluscos. Segundo Noelli (2000), a expansão territorial ocorreu através da lenta e contínua anexação de territórios adjacentes, tendo havido o transporte dos cultivos que eram introduzidos nas novas regiões conquistadas. Diferente da colonização realizada pelos caçadores e pelos sambaquieiros, o processo de expansão Tupi se dá em uma conjuntura bastante diferente, em um cenário com maior densidade demográfica e diversidade cultural.

Silva, Neves e De Blasis (2004:11) ressaltam a importância do mundo sobrenatural entre os Tupi que é habitado pelos espíritos, deuses e mortos. Para eles as fronteiras entre este domínio da sobrenatureza, o mundo dos homens e da natureza são indefinidos. Ao tentar estabelecer uma definição do modo de ser Tupi, ressaltam que povos agricultores, com uma organização social flexível, poder político baseado no prestígio e na importância religiosa do indivíduo, e que compartilham um mundo espiritual e ritual onde o xamanismo, a guerra e o canibalismo são noções extremamente importantes para a construção de sua identidade. A presença de outros grupos culturais é marcante nesse cenário e se coaduna com a organização de uma sociedade que se estruturava apoiada na guerra e no exocanibalismo.

O registro arqueológico marcante dos Tupi é a cerâmica, são tigelas pintadas de tamanhos variados com decoração plástica na superfície externa, principalmente na borda. Panelas, jarros, pratos e urnas usadas para buscar, armazenar e servir água e preparar bebidas fermentadas amplamente utilizadas nas cerimônias religiosas e utilizadas, também, para sepultar os corpos.

Pode-se propor que há duas categorias de cerimônia funerária, uma realizada para os próprios Tupi e a outra para os "outros", os inimigos.

Angela Buarque (no prelo) ao estudar o tratamento dos mortos nos sítios Tupinambá da região de Araruama, Rio de Janeiro, informa sobre a presença de urna com tampa associada a tigelas pintadas de formato e tamanho variados. Compunham a estrutura funerária fogueiras, buracos de estacas e a deposição de um sedimento especial para receber a urna no solo. A autora informa que nas peças abertas os desenhos são feitos, em sua grande maioria, na parte interna, que pode ser dividida em 3 regiões distintas o centro ou corpo da peça, a borda e o lábio. O motivo principal é desenvolvido no corpo da peça e os desenhos são feitos em linhas sinuosas muitas vezes entremeadas e realçadas por pontos, em geral na cor preta ou marrom. Além dos motivos em linhas sinuosas, estão presentes outros elementos geométricos como gregas, bastões, volutas, segmentos retos, algumas vezes paralelos e também oblíquos. A borda é um campo de decoração à parte. Em geral separada do corpo da peça por uma ou mais faixas nos diferentes tons de vermelho, sua decoração não guarda, necessariamente, similaridade com o motivo apresentado no corpo da tigela. São comuns as linhas retas dispostas paralelamente, por vezes entremeadas por linhas meândricas ou serpentiformes. Não é muito freqüente a decoração 
GASPAR, M.D. Cultura: comunicação, arte, oralidade na pré-história do Brasil. Rev. do Museu de Arqueologia e Etnologia, São Paulo, 14: 153-168, 2004.

no lábio, ocorre, às vezes, pintura vermelha ou a decoração plástica ungulada. Na maioria das vezes o lábio, plano, apontado ou redondo não recebe qualquer decoração.

Os cronistas oferecem vários relatos sobre as práticas funerárias entre os Tupinambá que pode ser aqui ilustrado com a citação de Soares de Souza (...) quando morre algum moço, filho de algum principal, que não tem muita idade, metemno em cócoras, atado os joelhos e barriga, em pote que ele caiba, e enterram o pote na mesma casa debaixo do chão, onde o filho e o pai, são chorados muito dias (Souza, 1971: 329). ${ }^{8}$ A descrição detalhada demonstra a persistência temporal da prática de sepultamento que se manteve após o devastador contato com os europeus.

As cenas relacionadas ao canibalismo, rito essencial da vida religiosa e social daquele povo, foram descritas pelos cronistas dos séculos XVI e XVII. Era praticado contra os inimigos que eram feitos prisioneiros, e contando com a participação de todos, homens, mulheres e crianças, inclusive convidados de outras aldeias, servindo para selar as alianças, encerrar as guerras e realizar tratados. Hans Staden fornece uma detalhada descrição do tratamento do corpo do inimigo, "Depois golpeia o prisioneiro na nuca, de modo que lhe saltam os miolos, e imediatamente levam as mulheres o morto, arrastam-no para o fogo, raspam-lhe toda a pele, fazendo-o inteiramente branco, e tapando-lhe o anus com um pau, a fim de que nada dele se escape. Depois de esfolado, toma-o um homem e

(8) Outros cronistas, também, fornecem descrição detalhada sobre o ritual funerário. Segundo Jean de Léry (1980: 247), "depois de aberta a cova, não comprida como as nossas, mas redonda e profunda como um tonel de vinho, curvam o corpo e amarram os braços em torno das pernas, enterrando-o quase de pé. Se o finado é pessoa de destaque sepultam-no na própria casa, envolvido em sua rede, juntamente com os seus colares, plumas e outros objetos de uso pessoal". Fernão Cardim informa que "!depois de morto o lavão, e pintão muito galante, como pintão os contrários e depois o cobrem de fío de algodão que não the parece nada, e lhe metem em cuya no rosto, e assentado o metem em um pote que para isso têm debaixo da terra, e o cobrem de terra, fazendo-lhe uma casa, aonde todos os dias lhe levão de comer, porque dizem que como cancã de bailar, vem ali comer, e assi os vão chorar por algum tempo todos os dias seus parentes, e com elle metem todas as suas jóias e metaras, para que as não veja ninguém, nem se lastime" (Cardim 1980: 94). corta-lhe as pernas, acima dos joelhos, e os braços junto ao corpo. Vêm então as quatro mulheres, apanham os quatro pedaços, correm com eles em torno das cabanas, fazendo grande alarido, em sinal de alegria. Separam após as costas, com as nádegas, da parte dianteira. Repartem isto entre si. As vísceras são dadas às mulheres. Fervem-nas e com o caldo fazem uma papa rala, que se chama mingau, que elas e as crianças sorvem. Comem essas vísceras, assim como a carne da cabeça" (Staden, 1974: 183)

Análises recentes do universo pictórico mostram que os desenhos feitos na parte mais visível da peça escondem e mostram a representação de partes do corpo humano (Silva, Neves, De Blasis, 2001; Buarque, no prelo; Prous, no prelo,). Vísceras e ossos emergem das linhas sinuosas entremeadas de pontos. A decoração atesta a manipulação e observação detida do corpo desmembrado em ritual antropofágico reservado ao inimigo. O "outro", ou as suas partes, incorporado através do canibalismo e da guerra foi perenizado na cerâmica. Guarda para todo o sempre um tema central para os Tupi.

\section{Conclusão}

As representações feitas pelos caçadores parecem ter sido movidas pelo desejo de perenizar o seu modo de vida. Materializar, sobrepor, impor aos outros os seus costumes, os seus ritos, mesmo que estes outros sejam animais como porcos-domato, veados ou tatu. As representações fazem referências a inúmeros aspectos da vida social rituais, danças, caça, nascimento, sexualidade. Se é possível sintetizar os temas representados vale dizer que as figuras parecem celebrar a vida social. A morte, muito embora ela esteja sugerida nas cenas de caça e talvez na de castigo, não é um tema central. É bem provável que a domesticação de um novo território e a imposição de seu estilo de vida (mesmo que seja frente aos animais) tenha sido o ponto chave do domínio pictórico.

Por sua vez, o cerne da sociedade sambaquieira parece ter sido garantir a preservação dos corpos, perspectiva que muito bem se coaduna em uma rotina social cujos ancestrais têm importância fundamental. Para os mortos foi criado local especial que se destaca na paisagem e se distingue de todos os outros. 
GASPAR, M.D. Cultura: comunicação, arte, oralidade na pré-história do Brasil. Rev. do Museu de Arqueologia e Etnologia, São Paulo, 14: 153-168, 2004.

Um grupo que gozava de estabilidade territorial certamente contava com um conhecimento profundo sobre o ambiente e os processos naturais com ele relacionados. O cemitério de Jabuticabeira-II esteve ativo por mais de oito séculos, seus usuários, que deveriam habitar as adjacências, tiveram tempo suficiente para observar e desenvolver conhecimento sistemático sobre a decomposição de corpos, sejam eles humanos ou não, já que este aspecto da morte parece ter sido tema de interesse para esta sociedade. Os sambaquieiros escolheram, para construir os cemitérios, material que assegurasse a preservação dos seus mortos. Com o acúmulo de conchas, criaram uma interferência no ambiente que neutralizou a acidez típica do solo brasileiro. Caso os sambaquieiros tivessem escolhido construir os cemitérios com material proveniente do próprio solo - uma matriz terrosa - nada restaria dos corpos.

É difícil mapear o conhecimento dos pescadores-coletores sobre os processos de decomposição dos corpos, mas Levi-Strauss (1970), ao refletir sobre a "ciência do concreto", chama a atenção sobre o profundo conhecimento de grupos nativos sobre a natureza. Embora não se possa comprovar que a preservação dos esqueletos foi o motivo que norteou a escolha das conchas como o principal material construtivo dos cemitérios, há indícios de que eles controlavam os processos após a morte. Covas eram revisitadas, ossos eram manipulados, retirados de outros locais para integrar um novo ritual funerário, ossos eram marcados e pintados. Esse mesmo cuidado com os corpos levou à construção de cercas no entorno das covas, a profundidade e a espessura das estacas impediram a ação de animais carniceiros e resultaram na preservação de esqueletos em posição anatômica.

A lógica da preservação associada à da visibilidade dos ancestrais que do alto controlavam o território sambaquieiro resultou em um programa funerário particular. O local de deposição do corpo era o topo do cemitério. Se alguma cova foi feita para receber o corpo, ela não ultrapassou os $20 \mathrm{~cm}$ de profundidade. Tudo em um sambaqui parece ter seguido a lógica de aumentar a altura do monumento e garantir maior visibilidade para os mortos. $\mathrm{O}$ fogo fúnebre, também, integra este princípio, as chamas e a fumaça também se projetam para cima. Da mesma forma, as visitas periódicas à área funerária e a sua cobertura com alimentos consumidos durante os festins fúnebres resultaram em incremento do monte

Na sociedade Tupinambá a questão do destino do corpo se coloca de outra maneira. Primeiro, a percepção do "outro" se impõe de maneira estruturadora para o funcionamento desta sociedade. Os mortos de dentro da comunidade têm tratamento distinto dos de fora, os primeiros são sepultados em urnas no interior da casa e os segundos são ingeridos. Processo de expansão territorial, ingestão do outro são partes de um mesmo sistema e estão bem representados nas cerâmicas. Embora tenham ocupado parte significativa da América do Sul os seus vasilhames são facilmente reconhecidos e a eles vinculados. São o melhor testemunho da expansão Tupi e do domínio de outros povos. Partes dos corpos quase que escondidos pelo emaranhado de linhas referem-se à manipulação das vísceras e ossos deste outro incorporado.

Caçadores celebram a vida social e mostram o poder em relação aos animais, sambaquieiros cultuam seus ancestrais e Tupinambá mostram e escondem, em suas cerâmicas, a incorporação do outro. Cada grupo, a seu modo, expressa em objetos pontos cruciais do seu viver em sociedade.

\section{Agradecimentos}

Agradeço a Angela Buarque pela leitura e sugestões, a Úrsula Farias pela elaboração das figuras e a Eliana Escórcio pela preparação da bibliografia. 
GASPAR, M.D. Cultura: comunicação, arte, oralidade na pré-história do Brasil. Rev. do Museu de Arqueologia e Etnologia, São Paulo, 14: 153-168, 2004.

GASPAR, M.D. Culture: communication, art, orality in the prehistory of Brazil. Rev. do Museu de Arqueologia e Etnologia, São Paulo, 14: 153-168, 2004.

ABSTRACT: This article has the objective of presenting reflections on artifacts from hunter-gatherers, sambaqui and Tubinambá backgrounds, that are distinctive to our eyes due to the strong esthetical appeal. They are rupestrian paintings, stone sculptures and ceramic pottery that, through the communication system printed in the material culture, eternize structural themes of these different societies.

UNITERMS: Rupestrian painting - Zooliths - Tupinambá pottery.

\section{Referências bibliográficas}

DE BLASIS, $\mathrm{P}$.

2001 Da era das glaciações às origens da agricultura. Catálogo da exposição Brasil 50 mil anos, uma viagem ao passado pré-colonial. São Paulo, EDUSP: 12-26.

FRANCHETTO, B.; LEITE, Y

2004 Origens da linguagem. Coleção Ciências Sociais, Passo-a-passo, 41. Rio de Janeiro: Jorge Zahar Editor

GASPAR, M.D.

2000 Sambaqui: arqueologia do litoral brasileiro Coleção Descobrindo o Brasil. Rio de Janeiro: Jorge Zahar Editor.

2003 a A arte rupestre no Brasil. Coleção Descobrindo o Brasil. Rio de Janeiro: Jorge Zahar Editor.

2003 b Aspectos da organização social de pescadorescoletores: região compreendida entre a Ilha grande e o delta do Paraíba do Sul, Rio de Janeiro. Pesquisas, São Leopoldo, 59: 1-163.

MARTIN, G

1996 Pré-história do nordeste do Brasil. Recife: Editora UFPE.

PEREIRA, E.

2002 Arte rupestre na Amazônia, Pará. Museu Paraense Emílio Goeldi. São Paulo: UNESP.

PESSIS, A.M.

2003 Imagens da Pré-história. São Paulo: FUMDHAM/ PETROBRÁS.

PROUS, A

1991 Arqueologia brasileira. Brasília: Editora UNB.

Relação bibliográfica essencial, porém mais extensa para que o leitor possa ter alguma referência caso se interesse por dados:

\section{BAHN, P.G}

1998 Rock Art. B.M. Fagan (Org.) The Oxford Companion to Archaeology. Nova York, Oxford University Press: 593-4.

1998 The Cambridge Illustrated History of
Prehistoric Art. Cambridge, Cambridge University Press.

BARRETO, C.

1999 Arqueologia brasileira: uma perspectiva histórica e comparada. Rev. do Museu de Arqueologia e Etnologia (Anais da I Reunião Internacional de Teoria Arqueológica na América do Sul). São Paulo, Universidade de São Paulo: 201-212.

2000 A construção do passado pré-colonial: uma breve história da arqueologia no Brasil. Dossiê antes do Cabral: arqueologia brasileira 1. Revista da USP, 32-51.

BEZERRADE MENESES, U.

1983 A cultura material no estudo das sociedades antigas. Revista de História, 115 (Nova Série), São Paulo, USP: 103-117

BUARQUE, A.

Prelo As estruturas funerárias dos sítios arqueológicos de Araruama. A. Prous; T.A. Lima (Eds.) Os ceramistas Tupiguarani.

CARDIM, F.

1980 Tratado da Terra e Gente do Brasil. São Paulo: Editora Itatiaia Ltda e Editora da Universidade de São Paulo, 206 pp.

CASTRO FARIA, L

1952 Sculptures en pierre des paléoaméridiens de la côte meridionale du Brésil: les zoolithes de Santa Catarina. In: CONGRESS INTAL DES SCIENCES ANTHROPOLOGIOUESETETHNOLOGIOUES (4: 1952). Actes. Viena. Vol 2:366-369.

1959 A arte animalista dos paleoameríndios do litoral sul do Brasil. Rio de Janeiro, Museu Nacional (Publicações avulsas: 24).

DE BLASIS, P.; EGGERS, S.; LAHR, M.M.; FIGUTI, L.;AFONSO, M.C.; GASPAR, M.D.

1998 Padrões de assentamentos e formação de sambaquis em Santa Catarina. Rev. do Museu de Arqueologia e Etnologia, 8: 319-321. 
GASPAR, M.D. Cultura: comunicação, arte, oralidade na pré-história do Brasil. Rev. do Museu de Arqueologia e Etnologia, São Paulo, 14: 153-168, 2004.

DE BLASIS, P.; FISH, S.K.; GASPAR, M.D.; FISH, P.R.

1998 Some references for the discussion of complexity among the sambaqui moundbuilders from the Southern shores of Brazil. Revista de Arqueologia Americana, Instituto Panamericano de Geografia e Historia, 15: 75-105.

DILLEHAY, T. D.

1997 Monte Verde: a late Pleistocene settlement in Chile. Vol. 2, The archaeological context Washington: Smithsonian Institution.

FISH, S.K.; DE BLAIS,P.; GASPAR, M.D.; FISH,P.R.

2000 Eventos incrementais na construção de sambaquis, litoral sul do estado de Santa Catarina. Rev. do Museu de Arqueologia e Etnologia, 10: 69-88.

FUNARI, P.P.

1999 A importância da teoria arqueológica internacional para a arqueologia sul-americana: o caso brasileiro. Rev. do Museu de Arqueologia e Etnologia (Anais da I Reunião Internacional de Teoria Arqueológica na América do Sul). São Paulo, Universidade de São Paulo: 213-221.

GASPAR, M.D.; AFONSO, M.; DE BLASIS, P.; EGGERS, S.; FIGUTI, L.; FISH, P.; FISH, S.; KLOKLER, D. M.; LAHR, M .M.; MORLEY, E.

1999 Uma breve história do projeto de pesquisa "Padrão de assentamento e formação de sambaquis: arqueologia e preservação em Santa Catarina". Revista do CEPA, 23 (29), jan./jun: 108-117.

GASPAR,M.D

1995 Zoólitos, Peixes e Moluscos - Cultura material e identidade social. Artesanías de América, 46-47: $81-96$

GEERTZ, C.A.

1978 Interpretação das culturas. Rio de Janeiro: Zahar Editores.

GUIDON, N

2004 Arqueologia da região do Parque Nacional Serra da Capivara. Antes - Histórias da Préhistória. Rio de Janeiro, Centro Cultural Banco do Brasil: 132-141.

HODDER, I

1982 Theoretical archaeology: a reactionary view. I. Hodder (Ed.) Symbolic and Structural Archaeology. Cambridge: Cambridge University Press.

1999 Interpreting Material Culture. In The The Archaeological Process. Oxford, Blackwell Publishers Ltda.: 66-78.

KIPNIS, R

1998 Early Hunter-gatherers in the Americas: Perspectives from Central Brazil. Antiquity, 72 (277): 581-592.

KLOKLER, D.M.

2001 Construindo ou deixando um sambaqui? Análises dos sedimentos de um sambaqui do litoral meridional brasileiro. Dissertação de Mestrado.
São Paulo, Faculdade de Filosofia, Letras e

Ciências Humanas, Universidade de São Paulo.

LÉRY, J. DE

1980 Viagem à terra do Brasil. São Paulo: Editora Itatiaia Ltda. e Editora da Universidade de São Paulo. 303 pp

LEVI-STRAUSS, C.

1970 O pensamento selvagem. São Paulo: Companhia Editora Nacional, EDUSP.

LIMA, T.A.

Prelo O Povoamento Inicial do Continente Americano: Migrações, Contextos, Datações H.P. Silva; C. Rodrigues-Carvalho (Orgs.) $O$

Povoamento das Américas: visões interdisciplinares. Rio de Janeiro: Zahar

NEVES, W.; PROUS, A.

2000 Arte: evolução ou revolução? In: Arte: Evolução ou Revolução? A primeira descoberta da América. Catálogo da Mostra do Descobrimento. São Paulo, Associação Brasil 500 Anos Artes Visuais: 28-39.

NOELLI, L.M.

2000 A ocupação humana da região Sul do Brasil: arqueologia, debates e perspectivas - 18722000. Dossiê antes do Cabral: arqueologia brasileira 2. Revista da USP: 218-269.

PARENTI, F.

1996 Problemática da pré-história do pleistoceno superior no nordeste do Brasil: Abrigo da Pedra Furada em seu contexto regional. FUMDHAMENTOS, Revista da Fundação Museu do Homem Americano, 1 (1): 15-53.

PESSIS, A.M.; GUIDON, N

2000 Registro rupestre e caracterização das etnias pré-históricas. L. Vidal (Org.) Grafismo indígena. São Paulo, EDUSP: 19-34.

PROUS, A.

1977 Les sculptures zoomorphes du sud brésilien et de 1'Uruguay. In: Cahiers d'Archéologie d'Amérique du Sud. Braga, CNRS, n. 5.

1992/93 Arquivos do Museu de História Natural. Universidade Federal de Minas Gerais, vol. XIII / XIV (vários artigos).

Prelo A pintura sobre cerâmica dos índios Tupiguarani. In:... (no prelo)

SILVA, F.A., NEVES, E.G.; DE BLASIS, P.

2004 Beleza, Rigor e Dignidade: A Cultura Material Tupi no Tempo e Espaço. Catálogo da Exposição Brasil Tupi no acervo do Museu de Arqueologia e Etnologia da USP. São Paulo, MAE - USP, Conjunto Cultural da Caixa: 1-31.

STADEN, H.

1974 Duas viagens ao Brasil. São Paulo, Editora Itatiaia Ltda e Editora da Universidade de São Paulo. 216 pp

TENÓRIO, M.C.; SOUSA, G.S

1971 Tratado Descritivo do Brasil em 1587, 4a ed., São Paulo, CEN e Editora da USP, v. 117. 